\title{
Screening for familial hypercholesterolaemia by measurement of apolipoproteins in capillary blood
}

\author{
F Skovby, S Micic, B Jepsen, S O Larsen, B Hansen, L Tegllund, B N Pedersen
}

\begin{abstract}
A total of 3025 families with schoolchildren aged $6-8$ years were offered pilot screening for familial hypercholesterolaemia by measurement of the concentrations of apolipoproteins A-1 and B in the children's capillary blood and by analysis of their family histories of early ischaemic heart disease. The concentrations of the apolipoproteins were determined by double rocket immunoelectrophoresis of an eluate of blood spotted on filter paper. Results were available from 2085 children. Because their B:A-1 ratio was above the 97.5 centile and their concentration of $B$ was above the 99th centile, 54 children (2.6\%) were selected to have their apolipoprotein concentrations reassessed. The 17 children $(0.8 \%)$ whose values were persistently above the chosen cut off points, and all of their available first and second degree relatives, had fasting determinations of serum lipid concentrations carried out. Raised serum concentrations of low density lipoprotein cholesterol and an autosomal dominant pattern of hypercholesterolaemia were found in $\mathbf{1 2}$ children and $\mathbf{1 0}$ families, respectively, suggesting a higher incidence of familial hypercholesterolaemia than the reported 1:500. Further investigations among family members disclosed hypercholesterolaemia in 29 relatives. A family history of early ischaemic heart disease was elicited by questionnaire, and was positive in only five of the 12 schoolchildren with hypercholesterolaemia.
\end{abstract}

We conclude that analysis of apolipoproteins from capillary blood spotted on filter paper is suitable for screening for familial hypercholesterolaemia, and that this method is more efficient than screening based on family history.

Heterozygous familial hypercholesterolaemia has an overall incidence in various populations of about 1:500, making it one of the most common inborn errors of metabolism. ${ }^{1}$ Affected adults have a significantly increased risk of early ischaemic vascular disease including fatal myocardial infarction. In people without known predisposition to hypercholesterolaemia, raised concentrations of total cholesterol and low density lipoprotein cholesterol, which are present from birth in familial hypercholesterolae$\mathrm{mia},{ }^{2}$ are strongly correlated with early (20 years old) atherosclerotic lesions in the aorta and coronary arteries. ${ }^{3}$ The apparent onset of atherosclerosis in childhood makes the detection and proper management of children with hypercho- lesterolaemia (including familial hypercholesterolaemia) a matter of concern to many paediatricians.

This paper describes a pilot screening programme for familial hypercholesterolaemia among schoolchildren by measuring the concentrations of apolipoproteins A-1 and B in capillary blood.

\section{Patients and methods}

In August 1987, 3025 families with children aged 6-8 years who were starting in the first grade of the Copenhagen school system were offered the chance to participate in a pilot screening programme for the detection of familial hypercholesterolaemia. The parents were asked to answer a questionnaire about the occurrence of coronary heart disease in their families. Upon completion of the questionnaire, the parents were requested to give their permission for blood samples to be taken from their child.

Capillary blood was obtained from the children without prior fasting between 8 am and 12 noon. About five drops of ear blood were collected on to filter paper (No 2992; Schleicher and Scholl), which was allowed to dry at room temperature for two hours, transported to the laboratory within six hours, and stored at $4^{\circ} \mathrm{C}$ in sealed plastic bags containing silica gel capsules until quantification of apolipoproteins on the next day.

Measurements were made by double rocket immunoelectrophoresis as previously described. ${ }^{4}$ After determination of the centile values for apolipoproteins, all children with ratios of $\mathrm{B}: \mathrm{A}$ 1 greater than the 97.5 centile or with a concentration of apolipoprotein B above the 99th centile were selected for repeat sampling of capillary blood and analysis of apolipoproteins. The children whose values were persistently above the chosen cut off points, and all their available first and second degree relatives, had venous blood taken after a 12 hour fast for analysis of the serum concentrations of total cholesterol, high density lipoprotein cholesterol, very low density lipoprotein cholesterol, and triglycerides as previously described. ${ }^{5}$ Low density lipoprotein cholesterol was calculated as total cholesterol minus the sum of high density lipoprotein cholesterol and very low density lipoprotein cholesterol. If the serum concentration of low density lipoprotein cholesterol in a child was above the 95 th centile for age, ${ }^{5}$ additional analyses of the lipid profile were done at intervals of at least three weeks. A physical examination was made, and appropriate laboratory tests

B N Pedersen 
were done to exclude causes of secondary hyperlipidaemia. The children with hypercholesterolaemia were offered follow up care in the paediatric lipid clinic.

The parents were asked to complete a questionnaire about the incidence of chest pains or coronary occlusions in themselves or their relatives (parents, sibling, aunts, and uncles). Information about the age at the time of the first symptom was requested. A positive family history of early ischaemic heart disease was defined as angina pectoris or myocardial infarction before the age of 50 in men, and before the age of 60 in women.

The study protocol was approved by the science and ethics committee of the Copenhagen City Hospitals.

\section{Results}

Of the 3025 questionnaires distributed, 2657 $(87.8 \%)$ were returned; the parents of 2166 $(71.6 \%)$ gave permission for capillary blood samples to be taken from their children. No information was given about the reasons why 491 families $(16 \cdot 2 \%)$ did not consent to the sampling of blood.

Measurements of apolipoproteins A-1 and B were successful in 2085 schoolchildren 6-8 years old. The cumulative distributions of the

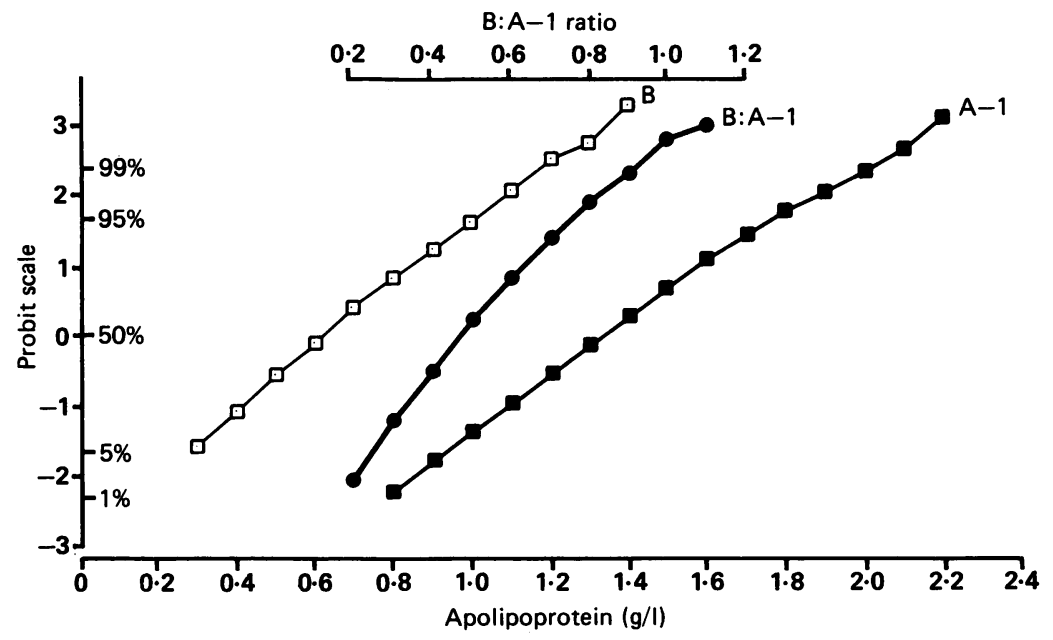

Cumulative distributions of apolipoprotein A-1, apolipoprotein $B$, and the ratio $B: A-1$ (probit scales; $n=2073$ ). The curves represent results from the first measurement of capillary apolipoproteins, excluding the 12 children later identified as having hypercholesterolaemia. observations and the B:A-1 ratio are shown as probit diagrams in the figure. The distributions of apolipoproteins B and A-1 are close to normal, whereas the distribution of the ratio is slightly skewed. Children with a B:A-1 ratio above the 97.5 centile (about 0.83 ) had their capillary apolipoprotein concentrations checked. Of the 47 children, 12 had a B:A-1 ratio that was persistently above $0 \cdot 83$. Only one of these 12 children had serum concentrations of total cholesterol and low density lipoprotein cholesterol below the 95th centile for Danish children of the same age group. ${ }^{5}$ The table shows the serum lipid concentrations in the other 11 children and their parents. In 10 families both the child and one parent had biochemical signs of type IIa hyperlipidaemia. One of these families was already known to have familial hypercholesterolaemia (case 87, table).

Among the 19 children with an apolipoprotein $B$ concentration above the 99th centile (about $1 \cdot 2 \mathrm{~g} / \mathrm{l}$ ), 12 also had a B:A-1 ratio of more than $0 \cdot 83$. On repeat measurement of capillary apolipoproteins, 11 of the 19 children had concentrations of apolipoprotein B consistently in the top centile; six of the 11 children also had a B:A-1 ratio of more than 0.83 . Subsequent analysis of serum lipid profiles from the 11 children showed that seven had type IIa hyperlipidaemia. Only one of the seven children (case 110, table) had not been detected because two subsequent B:A-1 ratios were above $0 \cdot 83$. Conversely, this criterion for selection identified three children with abnormally high concentrations of serum lipids but with an apolipoprotein B concentration below the 99 th centile (cases 98, 99, and 106, table).

Extensive family investigations disclosed 29 close relatives between 1 and 59 years of age with previously undiagnosed hypercholesterolaemia indicated by concentrations of low density lipoprotein cholesterol above the 95th centile for age and sex. ${ }^{6}$ In six. families such cases were identified in at least three generations. Three of four other families in which hypercholesterolaemia was documented in only two generations were immigrant families from which the grandparents were not available for lipid analysis; in the fourth family a paternal grandfather had died from a myocardial infarction at the age of 55. Thus in 10 families there was an autosomal dominant pattern of type IIa

Concentrations of capillary apolipoproteins and fasting serum lipid profiles in children with hypercholesterolaemia and their parents

\begin{tabular}{|c|c|c|c|c|c|c|c|c|c|c|c|c|c|c|c|}
\hline \multirow{3}{*}{$\begin{array}{l}\text { Case } \\
\text { No }\end{array}$} & \multicolumn{6}{|l|}{ Child } & \multirow{2}{*}{\multicolumn{3}{|c|}{$\begin{array}{l}\text { Father } \\
\text { Cholesterol (mmolll) }\end{array}$}} & \multirow{3}{*}{$\begin{array}{l}\text { Triglycerides } \\
\text { (momolll) }\end{array}$} & \multicolumn{4}{|l|}{ Mother } & \multirow{3}{*}{$\begin{array}{l}\text { Family } \\
\text { history of } \\
\text { ischaemic } \\
\text { heart } \\
\text { disease }\end{array}$} \\
\hline & \multicolumn{2}{|c|}{ Apolipoproteins (g/l) } & \multicolumn{3}{|c|}{ ) Cholesterol (mmolll) } & \multirow{2}{*}{$\begin{array}{l}\text { Triglycerides } \\
\text { (mmolll) }\end{array}$} & & & & & \multicolumn{3}{|c|}{ Cholesterol (mmolll) } & \multirow{2}{*}{$\begin{array}{l}\text { Trighycerides } \\
(\text { mmollt) }\end{array}$} & \\
\hline & $\begin{array}{l}\text { B:A-I } \\
\text { ratio }\end{array}$ & $\boldsymbol{B}$ & Total & $\begin{array}{l}\text { Low density } \\
\text { lipoprotein }\end{array}$ & $\begin{array}{l}\text { High density } \\
\text { lipoprotein }\end{array}$ & & Total & $\begin{array}{l}\text { Low density } \\
\text { lipoprotein }\end{array}$ & $\begin{array}{l}\text { High density } \\
\text { lipoprotein }\end{array}$ & & Total & $\begin{array}{l}\text { Low density } \\
\text { lipoprotein }\end{array}$ & $\begin{array}{l}\text { High density } \\
\text { lipoprotein }\end{array}$ & & \\
\hline 87 & 0.93 & $1 \cdot 30$ & $8 \cdot 2$ & $6 \cdot 7$ & $1 \cdot 1$ & $1 \cdot 2$ & $10 \cdot 1$ & $8 \cdot 7$ & $1 \cdot 0$ & 0.9 & \multirow{3}{*}{$\begin{array}{c}\text { Not } \\
\text { measured } \\
4 \cdot 3 \\
4.9 \\
4.9 \\
5 \cdot 3 \\
4.0 \\
9 \cdot 8 \\
\text { Not } \\
\text { measured } \\
11.6^{*} \\
6.3 \\
4.6 \\
6.9\end{array}$} & \multirow{3}{*}{$\begin{array}{l}\text { Not } \\
\text { measured } \\
2.3 \\
3.0 \\
3.1 \\
3.8 \\
2.1 \\
8.0 \\
\text { Not } \\
\text { measured } \\
10.5 \\
4.7 \\
3.2 \\
4.6\end{array}$} & \multirow{3}{*}{$\begin{array}{l}\text { Not } \\
\text { measured } \\
1.3 \\
1.6 \\
1.4 \\
1.5 \\
1.7 \\
0.9 \\
\text { Not } \\
\text { measured } \\
1.1 \\
1.4 \\
1.1 \\
1.8\end{array}$} & \multirow{3}{*}{$\begin{array}{l}\text { Not } \\
\text { measured } \\
1.0 \\
0.8 \\
0.9 \\
0.6 \\
0.5 \\
1.9 \\
\text { Not } \\
\text { measured } \\
0.5 \\
0.7 \\
0.6 \\
1.1\end{array}$} & Yes \\
\hline $\begin{array}{c}96 \\
97 \\
98 \\
99 \\
101 \\
102 \\
103\end{array}$ & $\begin{array}{l}0.95 \\
0.99 \\
0.96 \\
0.96 \\
0.96 \\
1.03 \\
1.38\end{array}$ & $\begin{array}{l}1.32 \\
1.29 \\
0.93 \\
0.98 \\
1.12 \\
1.57 \\
1.68\end{array}$ & $\begin{array}{l}7 \cdot 2 \\
6 \cdot 2 \\
6 \cdot 0 \\
6 \cdot 5 \\
6 \cdot 3 \\
8 \cdot 3 \\
9 \cdot 6\end{array}$ & $\begin{array}{l}5 \cdot 2 \\
4 \cdot 8 \\
4 \cdot 2 \\
4 \cdot 4 \\
5 \cdot 2 \\
6 \cdot 9 \\
8 \cdot 3\end{array}$ & $\begin{array}{l}1.4 \\
1.1 \\
1.2 \\
1.1 \\
1.0 \\
1.0 \\
1.0\end{array}$ & $\begin{array}{l}1 \cdot 3 \\
0.7 \\
1.2 \\
2.1 \\
0.6 \\
1.1 \\
0.8\end{array}$ & $\begin{array}{c}7 \cdot 2 \\
6 \cdot 0 \\
9 \cdot 0 \\
8 \cdot 6 \\
9 \cdot 6 \\
8 \cdot 3 \\
10 \cdot 2^{*}\end{array}$ & $\begin{array}{l}5 \cdot 5 \\
4 \cdot 2 \\
6 \cdot 6 \\
6 \cdot 7 \\
8 \cdot 2 \\
5 \cdot 7 \\
9 \cdot 0\end{array}$ & $\begin{array}{l}1.0 \\
1.1 \\
1.6 \\
1.0 \\
0.8 \\
1.7 \\
0.8\end{array}$ & $\begin{array}{l}2.6 \\
1.5 \\
1.4 \\
2.1 \\
1.5 \\
2.2 \\
1.4\end{array}$ & & & & & $\begin{array}{l}\text { No } \\
\text { Yes } \\
\text { No } \\
\text { Yes } \\
\text { No } \\
\text { No } \\
\text { Yes }\end{array}$ \\
\hline $\begin{array}{l}105 \\
106 \\
107 \\
110\end{array}$ & $\begin{array}{l}1.50 \\
0.91 \\
1.31 \\
0.80\end{array}$ & $\begin{array}{l}2.01 \\
1.07 \\
1.37 \\
1.39\end{array}$ & $\begin{array}{l}8 \cdot 8 \\
7 \cdot 0 \\
7 \cdot 6 \\
6 \cdot 8\end{array}$ & $\begin{array}{l}7 \cdot 6 \\
5 \cdot 6 \\
6 \cdot 4 \\
4 \cdot 9\end{array}$ & $\begin{array}{l}1.0 \\
0.9 \\
1.1 \\
1.5\end{array}$ & $\begin{array}{l}0.7 \\
1.3 \\
0.6 \\
0.8\end{array}$ & $\begin{array}{c}5 \cdot 6 \\
13 \cdot 2 \\
6.5^{*} \\
5 \cdot 8\end{array}$ & $\begin{array}{l}4 \cdot 1 \\
9 \cdot 1 \\
5 \cdot 2 \\
4 \cdot 4\end{array}$ & $\begin{array}{l}1 \cdot 2 \\
1 \cdot 0 \\
0 \cdot 7 \\
1 \cdot 1\end{array}$ & $\begin{array}{l}0.9 \\
5 \cdot 7 \\
1 \cdot 5 \\
0.8\end{array}$ & & & & & $\begin{array}{l}\text { No } \\
\text { No } \\
\text { No } \\
\text { Yes }\end{array}$ \\
\hline
\end{tabular}

*Xanthelasmata. 
hyperlipidaemia. In the remaining two families (cases 97 and 107, table) parental lipid analyses showed concentrations of low density lipoprotein cholesterol below the 95th centile for age and sex.

The children listed in the table were all normal on physical examinations, except for one child who was obese (case 98). Laboratory investigations of the causes of secondary hyperlipidaemia were unrevealing. All but one of the families were interested in counselling and follow up for the children with hypercholesterolaemia. Information about risk factors for atherosclerotic vascular disease and about the principles behind a diet to lower blood cholesterol concentrations was offered by the physician in the paediatric lipid clinic. Particular emphasis was placed on a reduction of the intake of saturated fats from meat and dairy products, because both of these feature largely in the traditional Danish diet. The children were then seen at three to six month intervals and height, weight, and lipid profile were measured. After six to 12 months a three day dietary history was recorded by a dietitian, and the daily intakes of energy, saturated and polyunsaturated fats, and cholesterol were calculated. Further advice depended upon the reduction of total and low density lipoprotein cholesterol concentrations achieved and on the dietary history. Two years after diagnosis no child had required hyperlipidaemic drugs.

Analysis of the 2657 completed questionnaires disclosed a history of early ischaemic heart disease in 398 families (15.0\%). Of the 491 families who did give permission for blood samples to be taken from their children, 27 gave a positive family history by questionnaire $(5 \cdot 5 \%)$. Only five of the 12 children identified as having hypercholesterolaemia by apolipoprotein analysis had a positive family history of early ischaemic heart disease on the questionnaire.

\section{Discussion}

According to official recommendations screening of children for hypercholesterolaemia should be directed at high risk groups-that is, those with a family history of cardiovascular disease or hyperlipidaemia. ${ }^{7}$ Several concerns have been raised about a low risk, population based approach, including the cost of techniques for measuring cholesterol and the ability of the tests to detect all children with raised low density lipoprotein cholesterol concentrations. Andersen et al have shown that it is feasible to screen newborns for hyperlipoproteinaemia by measuring very low density lipoprotein and low density lipoprotein cholesterol concentrations in cord blood, a method which is impractical for routine neonatal screening. ${ }^{9}$ More recently, newborn infants have been screened for familial hypercholesterolaemia by measurement of apolipoprotein B in capillary blood. ${ }^{10}$ The methods used in the present study were developed for the same purpose-that is, to screen newborns for familial hypercholesterolaemia using blood from the filter paper currently used in Denmark to screen for phenylketonuria and congenital hypothyroidism. The method used for analysis of apolipoproteins is based on immunological quantification of these substances from small amounts of capillary blood easily obtained from infants, and it is suitable for screening a large number of children. ${ }^{4}$

Familial hypercholesterolaemia is characterised by raised serum low density lipoprotein cholesterol concentration. Direct measurement of this lipoprotein is difficult, and an estimate based on the serum values of other lipid fractions requires larger amounts of blood than are normally. obtainable from capillary samples. Several studies have suggested that the circulating concentration of apolipoprotein B, the apoprotein of low density lipoprotein, is a better predictor of premature coronary artery disease than is the total plasma cholesterol concentration. ${ }^{11}$ The absolute concentrations of apolipoproteins in blood absorbed in filter paper cannot be determined accurately because the precise volume of blood is not known. ${ }^{4}$ This difficulty is circumvented by the simultaneous measurement of apolipoprotein A-1 and the use of the $\mathrm{B}: \mathrm{A}-1$ ratio as the criterion for detection of familial hypercholesterolaemia. In capillary blood from 68 such patients aged $4-42$ years we have previously found the B:A-1 ratio to be consistently above $0 \cdot 90 .^{4}$ We therefore took the ratio of 0.83 , or the 97.5 centile of our study group, as the threshold for recall so that we had a wide enough margin to avoid false negative results. Our data did not allow an estimate of the number of false negative results - that is we cannot find out how many children with B:A-1 ratios below 0.83 have hypercholesterolaemia. None the less, the unexpected high incidence of familial cases of hypercholesterolaemia (about 1:200 compared with the usually reported incidence of familial hypercholesterolaemia of about $1: 500^{1}$ ) suggests that the number of false negative results is small. It is possible that some of the children detected have hypercholesterolaemia that is not low density lipoprotein receptor deficient heterozygous familial hypercholesterolaemia-for example, familial combined hyperlipidaemia or inherited defects of apolipoprotein B. Although the data presented in the table favour the diagnosis of familial hypercholesterolaemia in most cases, this can be confirmed only by direct assay of the number or the molecular structure of low density lipoprotein receptors in cells from affected patients.

Only five of the 10 children with documented parental hypercholesterolaemia had family histories of early ischaemic heart disease (table). The lack of such information in the other families could be explained in several ways. Many people with hypercholesterolaemia do not develop signs of coronary disease until they are in their sixties or later, and they would not have contributed to a positive family history by our criteria. A proportion of subjects heterozygous for familial hypercholesterolaemia live to old age protected by factors as yet unknown from their raised low density lipoprotein cholesterol concentrations and thus from fatal ischaemic heart disease. ${ }^{12}$ Whereas the high familial correlation between early coronary deaths and familial hypercholesterolaemia makes a strong case for proper management of children with a posi- 
tive family history, the need to identify and perhaps treat affected children without such a history is less obvious. ${ }^{12}$ Finally, and most likely, there may have been under-reporting of ischaemic heart disease in the questionnaires because of the poor reliability of anecdotal family medical information. ${ }^{13}$

Screening of adults for hypercholesterolaemia is a controversial issue, let alone screening of children. In view of the serious long term prognosis, however, we believe that screening for familial hypercholesterolaemia is justified at any age. Dietary habits are established in childhood, and affected children are likely to benefit from a prudent diet; some may also benefit from medical treatment. Our results support the conclusion drawn from several recent studies of hypercholesterolaemia in children-namely, that selective screening based on family history is inadequate as only about half of all children with hypercholesterolaemia are identified. ${ }^{14-16}$ In contrast to screening of adults for hypercholesterolaemia, the usefulness of total serum cholesterol concentration as a screening test for raised low density lipoprotein cholesterol concentrations in children is limited by the higher concentrations of high density lipoprotein cholesterol in many children and adolescents than in adults. ${ }^{17}$ Apolipoprotein $B$ has test characteristics superior to those of total cholesterol concentration in detecting raised concentrations of low density lipoprotein cholesterol in serum. ${ }^{18}$ Our findings confirm the feasibility of using measurement of capillary apolipoproteins as a screening test for hypercholesterolaemia in children.

We dedicate this paper to the memory of Dr GE Andersen, who initiated the study. Inger Jeppesen, Lis Vejbæk, Winni Sabro, and Alice Nielsen gave us superb technical assistance. Our colleagues in the paediatric consultation service of the Copenhagen school system were most helpful in the collection of blood samples. Financial support was provided by Helsefonden and the Danish Heart Association.
1 Goldstein JL, Brown MS. Familial hypercholesterolemia. In Scriver CR, Beaudet AL, Sly WS, Valle D, eds. The metabolic basis of inherited disease. New York: McGraw-Hill, 1989:1215-50.

2 Kwiterovich PO Jr, Levy RI, Frederickson DS. Neonatal diagnosis of familial type II hyperlipoproteinemia. Lancet 1973;i:118-21.

3 Newman WP, Freedman DS, Voors AW, et al. Relation of serum lipoprotein levels and systolic blood pressure to early atherosclerosis. The Bogalusa heart study. $N$ Engl f Med 1986;314:138-44.

4 Micic S, Arends J, Nørgaard-Pedersen B, Christoffersen $K$, Andersen GE. Simultaneous quantification by double in blood spotted on filter paper. Clin Chem 1988;34: in blood

5 Ibsen KK, Lous P, Andersen GE. Lipids and lipoproteins in 350 Danish schoolchildren, ages 7 to 18 years. Acta Paediatr Scand 1980;69:231-3.

6 Appleyard $M$, ed. The Copenhagen city heart study: Østerbroundersøgelsen. Scand F Soc Med 1989;17(suppi 41):80-4.

7 American Academy of Pediatrics, Committee on Nutrition. Indications for cholesterol testing in children. Pediatrics 1989;83:141-2.

8 British Cardiac Society. Report of British Cardiac Society work ing groups on coronary disease prevention. London: British Cardiac Society, 1987

9 Andersen GE, Lous P, Friis-Hansen B. Screening for hyperlipoproteinemia in 10000 Danish newborns. Acta Paediatr Scand 1979;68:541-5.

10 Blades BL, Dudman NPB, Wilcken DEL. Screening for familial hypercholesterolaemia in 5000 neonates: a recall study. Pediatr Res 1988;23:500-4.

11 Editorial. Apolipoprotein-B and atherogenesis. Lancet 1988; i: $1141-2$.

12 Heiberg A, Slack J. Family similarities in the age at coronary deaths in familial hypercholesterolaemia. BMF 1977;ii: 493-5

13 Napier JA, Metzner H, Johnson BC. Limitations of morbidity and mortality data from family histories - a report from the Tecumseh community health study. Am $\mathcal{F}$ Public Health 1972;62:30-5.

14 Griffin TC, Christoffel KK, Binns HJ, McGuire PA, The Pediatric Practice Research Group. Family history evaluation as a predictive screen for childhood hypercholesterolemia. Pediatrics 1989;84:365-73.

15 Dennison BA, Kikuchi DA, Srinivasan SR, Webber LS, Berenson GS. Parental history of cardiovascular disease as an indication for screening for lipoprotein abnormalities in children. I Pediatr 1989;115:186-94.

16 Garcia RE, Moodie DS. Routine cholesterol surveillance in childhood. Pediatrics 1989;84:751-5.

17 Dennison BA, Kikuchi DA, Srinivasan SR, Webber LS Berenson GS. Serum total cholesterol for the detection of elevated low-density lipoprotein in children and adolescents: the Bogalusa heart study. Pediatrics 1990;85:472-9

18 Dennison BA, Kikuchi DA, Srinivasan SR, Webber LS, Berenson GS. Measurement of apolipoprotein B as a screening test for identifying children with elevated levels of low-density lipoprotein cholesterol. $\mathcal{F}$ Pediatr 1990;117: 358-63. 